\title{
In Vivo NMDA Receptor Activation Accelerates Motor Unit Maturation, Protects Spinal Motor Neurons, and Enhances SMN2 Gene Expression in Severe Spinal Muscular Atrophy Mice
}

\author{
Olivier Biondi, ${ }^{1 \star}$ Julien Branchu, ${ }^{1 \star}$ Gabriel Sanchez, ${ }^{3}$ Camille Lancelin, ${ }^{1}$ Séverine Deforges, ${ }^{1}$ Philippe Lopes, ${ }^{1,2}$ \\ Claude Pariset, ${ }^{1}$ Sylvie Lécolle, ${ }^{1}$ Jocelyn Côté, ${ }^{3}$ Christophe Chanoine, ${ }^{1}$ and Frédéric Charbonnier ${ }^{1}$ \\ ${ }^{1}$ Université Paris Descartes, Centre Universitaire des Saints-Pères, Laboratoire de Neurobiologie des Réseaux Sensorimoteurs, Unité Mixte de Recherche \\ 7060, Centre National de la Recherche Scientifique, F-75270 Paris Cedex 06, France, ${ }^{2}$ Université d'Evry-Val-d'Essonne, F-91025 Evry, France, and ${ }^{3}$ Centre \\ for Neuromuscular Disease and Department of Cellular and Molecular Medicine, Faculty of Medicine, University of Ottawa, Ottawa, Ontario K1H 8M5, \\ Canada
}

\begin{abstract}
Spinal muscular atrophy (SMA), a lethal neurodegenerative disease that occurs in childhood, is caused by the misexpression of the survival of motor neuron (SMN) protein in motor neurons. It is still unclear whether activating motor units in SMA corrects the delay in the postnatal maturation of the motor unit resulting in an enhanced neuroprotection. In the present work, we demonstrate that an adequate NMDA receptor activation in a type 2 SMA mouse model significantly accelerated motor unit postnatal maturation, counteracted apoptosis in the spinal cord, and induced a marked increase of SMN expression resulting from a modification of SMN2 gene transcription pattern. These beneficial effects were dependent on the level of NMDA receptor activation since a treatment with high doses of NMDA led to an acceleration of the motor unit maturation but favored the apoptotic process and decreased SMN expression. In addition, these results suggest that the NMDA-induced acceleration of motor unit postnatal maturation occurred independently of SMN. The NMDA receptor activating treatment strongly extended the life span in two different mouse models of severe SMA. The analysis of the intracellular signaling cascade that lay downstream the activated NMDA receptor revealed an unexpected reactivation of the CaMKII/AKT/CREB (cAMP response element-binding protein) pathway that induced an enhanced SMN expression. Therefore, pharmacological activation of spinal NMDA receptors could constitute a useful strategy for both increasing SMN expression and limiting motor neuron death in SMA spinal cord.
\end{abstract}

\section{Introduction}

Spinal muscular atrophy (SMA) is a very severe autosomal recessive disease in childhood for which no efficient therapy is currently available. SMA is characterized by a specific loss of spinal motor neurons leading to a severe muscular weakness and death when vital muscles are affected (Crawford and Pardo, 1996). SMA is caused by mutation of the survival of motor neuron 1 (Smn1) gene (Lefebvre et al., 1995) leading to a deficiency of the survival of motor neuron (SMN) protein expression. All patients

\footnotetext{
Received April 7, 2010; revised May 31, 2010; accepted June 16, 2010.

This work was supported by a fellowship from Ministère de la Recherche et de la Technologie (0.B., J.B.). J.C. is a Canada Research Chair (Tier 2) in RNA Metabolism funded through Canadian Institutes for Health Research Operating Grant MOP-86746. G.S. is the recipient of a postdoctoral fellowship from I'Association Française contre les Myopathies. We thank Hung Li for his fruitful collaboration for all the past years. We thank C. Legay for the kind gift of the MBI muscle cells and B. Lamotte d'Incamps for his help in installing the coculture system. We also thank V. Mouly and S. Lefebvre for the antibodies and C.-L. Gallien and P.-P. Vidal for their comments and advice.

${ }^{*} 0$.B. and J.B. contributed equally to this work.

Correspondence should be addressed to Frédéric Charbonnier, Université Paris Descartes, Centre Universitaire des Saints-Pères, Laboratoire de Neurobiologie des Réseaux Sensorimoteurs, Unité Mixte de Recherche 7060, Centre National de la Recherche Scientifique, 45 rue des Saints-Pères, F-75270 Paris Cedex 06, France. E-mail: frederic.charbonnier@parisdescartes.fr.

DOI:10.1523/JNEUROSCI.1764-10.2010

Copyright $\odot 2010$ the authors $\quad 0270-6474 / 10 / 3011288-12 \$ 15.00 / 0$
}

retain one or more copies of the $S m n 2$ gene, which modulates the disease severity by allowing a small amount of full-length SMN transcripts and stable SMN protein to be produced (Lorson and Androphy, 2000). Several recent reports indicate that a low level of SMN protein impairs the motor system postnatal development in mice (Biondi et al., 2008; Kariya et al., 2008; Kong et al., 2009) and in patients (Martínez-Hernández et al., 2009). Whether this delay in postnatal development is a leading factor in SMA physiopathology is still a matter of debate. In this respect, modulating the activation of the signaling cascade triggered by the NMDA subtype of ionotropic glutamate receptors (NMDARs) could provide relevant elements for solving this controversy. Indeed, several studies based on NMDAR inhibition strategies pointed out the major role of NMDAR-mediated signaling in (1) triggering the activity-dependent postnatal maturation of motor neurons (MNs) (Kalb and Hockfield, 1992; Kalb, 1994) and (2) preventing apoptosis in developing neurons (Ikonomidou et al., 1999; Lladó et al., 1999). Likewise, impairing NMDAR activity in type 2 SMA-like mice limits the exercise-induced acceleration of the motor unit maturation and partly prevents exercise-induced neuroprotection (Biondi et al., 2008). Surprisingly, the effects of a direct and specific activation of NMDAR on motor unit matu- 
ration have never been investigated in vivo, even in wild-type mice.

Furthermore, the NMDAR signaling pathway could activate neuroprotective mechanisms and possibly enhance the SMN2 gene expression in SMA motor neurons. The precise intracellular signaling pathways triggered by NMDARs still remain unexplored in spinal motor neurons. Yet it can be speculated from data collected from granular and hippocampal cell cultures that the extracellular signal-regulated kinase (ERK) and the phosphatidylinositol 3-kinase (PI3K)/AKT kinase pathways might be activated downstream the receptor (Lee et al., 2005; Papadia and Hardingham, 2007). Interestingly, both pathways can in theory recruit the cAMP response element-binding protein (CREB), a powerful activator of neuron prosurvival transcription factor on the one hand (Hardingham et al., 2002; Lee et al., 2005; Papadia et al., 2005) and an efficient transactivator of the Smn gene in vitro on the other (Majumder et al., 2004). Moreover, it is well known that the activation of the NMDAR results in an increase in the mouse Smn gene expression in wild-type neuron cultures (Andreassi et al., 2002).

The present study provides the first experimental lines of evidence indicating that an adequate activation of NMDAR in several SMA-like mice can delay cellular symptom progression, accelerating the motor unit postnatal maturation, limiting the apoptotic process, and enhancing SMN expression in SMA spinal cord.

\section{Materials and Methods}

Mice and treatments. The knock-out transgenic type 2 SMA-like mice $\left(S m n^{\Delta 7 / \Delta 7}, S M N 2^{+/+}\right)$derive from mice obtained from the Institute of Molecular Biology (Hsieh-Li et al., 2000) (Academia Sinica, Taipei, Taiwan). To standardize the type 2 phenotype, male and female mutant mice with a weight ranging from 3 to $4 \mathrm{~g}$ at $8 \mathrm{~d}$ of age were used for this study as previously described (Biondi et al., 2008). A vehicle-treated group $(n=64)$ and a NMDA-treated group $(n=109)$ of type 2 SMA-like mice were randomly constituted in a blind systematic manner to minimize bias. The control mice were heterozygous knock-out for Smn with the human SMN2 transgene $\left(S m n^{+/ \Delta 7}, S M N 2^{+/+} ; n=70\right)$. The type 1 SMA-like mice containing two human SMN2 transgenes and the mouse Smn knock-out were purchased from the The Jackson Laboratory and genotyped as previously described (Monani et al., 2000). Mouse genotypes were as follows: type 1 SMA-like mice $\left(\mathrm{Smn}^{-1-}, \mathrm{SMN}^{+/+}\right)(n=$ $58)$ and controls $\left(\mathrm{Smn}^{-/+}, \mathrm{SMN} 2^{+/+}\right)(n=29)$.

To evaluate the benefits of NMDAR activation on SMA, postnatal day 8 (P8) neonatal control and type 2 SMA-like mice, and P1 neonatal control and type 1 SMA-like mice, were injected intrathecally with either 5 (referred as low dose) or 25 (referred as toxic dose) pmol of NMDA $(100 \mu \mathrm{M})$ (Sigma-Aldrich) in $0.5 \mu \mathrm{l} / \mathrm{g}$ of $0.9 \% \mathrm{NaCl}$ dyed in Evans blue per gram. These mice were compared, control and SMA-like mice injected from $\mathrm{P} 8$ or P1 with $0.5 \mu \mathrm{l} / \mathrm{g}$ of $0.9 \% \mathrm{NaCl}$ dyed in Evans blue. Body weight and life span recordings were performed every day until the death of the animal. The animals were considered to be dead when mice were no longer able to stand up $20 \mathrm{~s}$ after having been placed on their sides. For the cellular studies, NMDA-treated and vehicle type 2 SMA-like mice were compared at P12, whereas $\mathrm{P} 2$ vehicle type 1 SMA-like mice were compared with P6 NMDA-treated type 1 SMA-like mice, to deal with the very short life span of vehicle type 1 SMA-like mice $(\sim 2 \mathrm{~d})$ and the need for an appropriate duration of the NMDA treatment to be able to analyze its effects. Spinal cord of mice was systematically removed and assayed for the Evans blue staining within the spinal cord (supplemental Fig. 1, available at www.jneurosci.org as supplemental material).

The care and treatment of animals followed the national authority (Ministère de la Recherche et de la Technologie, France) guidelines for the detention, use, and the ethical treatment of laboratory animals. The in vivo NMDA injection was approved by the local ethic committee (number P2.CC.034.07).
Cell cultures and treatments. Cocultures of spinal cord explants (1 $\mathrm{mm}^{3}$ ) and muscle cells were performed as described by Kobayashi et al. (1987) with the following modifications. Spinal cord explants were obtained from control and severe SMA embryonic mice. Explants from the whole transverse slices of 10.5-d-old mice embryo spinal cords including dorsal root ganglia (DRGs) were placed on the muscle monolayer. DRGs are essential to ensure a good innervation ratio (Kobayashi et al., 1987). The muscle culture was established through the differentiation of the wild-type muscle cell line made MBI (Cartaud et al., 2004). Myoblast cells were cultured on $35 \mathrm{~mm}$ Petri dish at $33^{\circ} \mathrm{C}$ in $8.5 \% \mathrm{CO}_{2}$ in DMEM supplemented with $2 \mathrm{~mm}$ glutamine, $20 \%$ horse serum, $10 \%$ fetal bovine serum, $2 \%$ penicillin/streptomycin (5000 U), and $20 \mathrm{U} / \mathrm{ml} \gamma$-interferon (Roche Diagnostics). All the culture medium reagents were purchased from Invitrogen. Confluent myoblasts were differentiated into myotubes in the same medium without interferon [differentiation medium (DM)]. After 5-7 d in DM, spinal cord explants were added on the cultured contracting muscle cells. After coculture with spinal cord, the culture was kept in DM. All cocultures were fed three times a week and examined daily by phase-contrast inverted microscopy to check the appearance of the innervation. The presence of neuromuscular junctions (NMJs) was detected with Alexa Fluor 568-conjugated $\alpha$-bungarotoxin and the axonal growth was observed through immunodetection using an antineurofilament and anti-synaptophysin primary antibodies as described below.

Stimulation of the NMDARs was achieved by exposing cells to $100 \mu \mathrm{M}$ NMDA. Specific blockade of synaptic NMDARs was achieved using 10 $\mu \mathrm{M}$ (+)-5-methyl-10,11-dihydro-5H-dibenzo $[a, d]$ cyclohepten-5,10imine maleate (MK801) (Sigma-Aldrich) in $\mathrm{Mg}^{2+}$-free medium, followed by a thorough $1 \mathrm{mM} \mathrm{MgCl}_{2}$ wash to fully remove MK801. To evaluate the $\mathrm{Ca}^{2+}$ dependency, extracellular $\mathrm{Ca}^{2+}$ chelator EGTA $(5 \mu \mathrm{M})$ (Sigma-Aldrich) and cell-permeable $\mathrm{Ca}^{2+}$ chelator BAPTA-AM $(10 \mu \mathrm{M})$ (Invitrogen) were added to the culture. The role of key signaling enzymes was achieved by the treatment of cocultures by specific inhibitor, the CaMKII inhibitor $N$-[2-[N-(4-chlorocinnamyl)- $N$-methylaminomethyl] phenyl]-N-(2-hydroxyethyl)-4-methoxybenzenesulfonamide phosphate salt $(\mathrm{KN}-93)(10 \mu \mathrm{M})$ (Calbiochem), the mitogen-activated protein kinase (MAPK)/ERK kinase (MEK) inhibitor 1,4-diamino-2,3dicyano-1,4-bis(2-aminophenylthio)butadiene (U0126) (10 $\mu \mathrm{M})$ (Promega), and the PI3K inhibitor 2-morpholin-4-yl-8-phenylchromen-4one (LY294002) (100 $\mu \mathrm{M})$ (Calbiochem).

After $5 \mathrm{~d}$ of treatment, explants were mechanically removed from the muscle layer, and proteins were purified and analyzed by Western blot as described below. The absence of muscle cell contamination in the explant fraction was checked by probing the Western blot with a myogenin antibody (1:500; Santa Cruz Biotechnology) and a tropomyosin I antibody (1:5000; Santa Cruz Biotechnology) (supplemental Fig. 2, available at www.jneurosci.org as supplemental material).

Behavioral testing in NMDA-treated type 2 SMA-like mice. The grip strength was performed in the forelimb of control mice and vehicle- and NMDA-treated type 2 SMA-like mice from P8 to death. All the tests were made blind, the group assignment being unknown to the observers. The time spent holding onto a thin metal rod suspended in midair was calculated. Each mouse was subjected to five successive attempts separated by a 10 min rest period.

The ambulatory behavior was assessed in an open-field test for all groups. The apparatus consisted of a wooden box measuring $28 \times 28 \times$ $5 \mathrm{~cm}$. The floor of the arena was divided into $167 \times 7 \mathrm{~cm}$ squares. The squares that were immediately adjacent to the walls were referred to as periphery, and the four remaining squares were referred to as center. The mice were tested individually, and the open field was washed after each session. Each mouse initially placed in the center of the open field was allowed to move freely for $5 \mathrm{~min}$. The behavioral measures recorded manually by the experimenter during these $5 \mathrm{~min}$ were the number of peripheral and central square crossings.

Histological and immunohistochemical analysis. Anesthetized animals were submitted to an intracardial perfusion of $40 \mathrm{ml}$ of PBS solution at $1.2 \mathrm{ml} \cdot \mathrm{min}^{-1}$ followed by $40 \mathrm{ml}$ of $4 \%$ PFA solution diluted in PBS solution at the same flow. Then spinal cords were dissected and incubated overnight in 4\% PFA solution and washed twice for $2 \mathrm{~h}$ with PBS. 
The lumbar spinal cords (L1 to L5) were embedded in $4 \%$ agarose solution in sterilized water for $30 \mathrm{~min}$ at $4^{\circ} \mathrm{C}$. Fifty micrometer sections were then performed using a vibratome on the whole length of the sample. One of every five sections (an average of 30 sections examined corresponding to $\sim 600 \mathrm{MNs}$ per animal and $\sim 5000$ MNs per experimental point) was processed for immunohistochemical analysis. Tissue sections were incubated for $1 \mathrm{~h}$ at room temperature in a blocking solution [7\% normal donkey serum with $0.5 \%$ Triton X-100 in Tris-buffered solution (TBS)]. Motor neuron immunodetection was performed using a choline acetyltransferase (ChAT) primary antibody (polyclonal goat anti-ChAT; 1:200; Millipore Bioscience Research Reagents) for $2 \mathrm{~d}$ at $4^{\circ} \mathrm{C}$. Sections were washed between each subsequent step with $0.5 \%$ Triton X-100 in TBS. Sections were subsequently incubated with an Alexa Fluor 568 donkey anti-goat Ig (1:400; Jackson ImmunoResearch) for $1 \mathrm{~h}$ at room temperature. The sections were washed three times for $10 \mathrm{~min}$ in TBS and mounted in Vectashield mounting medium with DAPI (4',6'-diamidino-2-phenylindole) (Vector Laboratories). The staining specificity was checked in control incubations performed in the absence of the primary antibody.

For motor endplate labeling, whole-mount preparations of muscle fibers $(\sim 200 \mathrm{NMJs}$ per muscle and per animal; $\sim 1000$ NMJs per experimental point) or cocultures were stained using Alexa Fluor 568-conjugated $\alpha$-bungarotoxin $(4 \mathrm{mg} / \mathrm{ml}$ in PBS with $4 \%$ bovine serum albumin). Presynaptic motor nerve terminals were stained with monoclonal rabbit antibodies directed against the $145 \mathrm{kDa}$ isoform of neurofilament light protein (NN18; 1:500; Millipore Bioscience Research Reagents) and synaptophysin (1:5; Invitrogen). The whole-mount preparations were subsequently incubated with an Alexa Fluor 488 goat anti-rabbit IgG (1:400; Invitrogen) for $1 \mathrm{~h}$ at room temperature.

For muscle typology, cryostat sections (one transversal medial section per muscle and per animal, which represented $\sim 4000,6000$, and 12,000 muscle fibers in the soleus, the plantaris, and the tibialis, respectively, for each experimental point) were incubated with mouse monoclonal antibodies raised against myosin heavy chains (MyHCs) (1) embryonic (F1.652; University of Iowa, Iowa City, IA) and (2) neonatal MHC isoforms (N3.36; University of Iowa) at a dilution of 1:20 for $1 \mathrm{~h}$ at room temperature and washed three times in PBST (PBS containing $0.1 \%$ Tween 20 ). Sections were then incubated at room temperature with a rabbit anti-mouse Ig conjugated with FITC (1:20; Sigma-Aldrich) for $1 \mathrm{~h}$. After washing with PBS, sections were mounted in Vectashield Mounting Medium (Vector Laboratories).

All counts were performed using NIH ImageJ software, version 1.37. Color images were tinted using Image Pro-Plus software, in which identical brightness, contrast, and color balance adjustments were applied to all groups.

Microscopy. All immunofluorescence images were collected with a CCD camera (QImaging Retiga 2000R Fast; Cooled Mono 12 bit) mounted on Olympus microscope (BX51) using the Image Pro-Plus, version 6.0, software (Media Cybernetics) with $40 \times(4 \times$ Olympus ob-
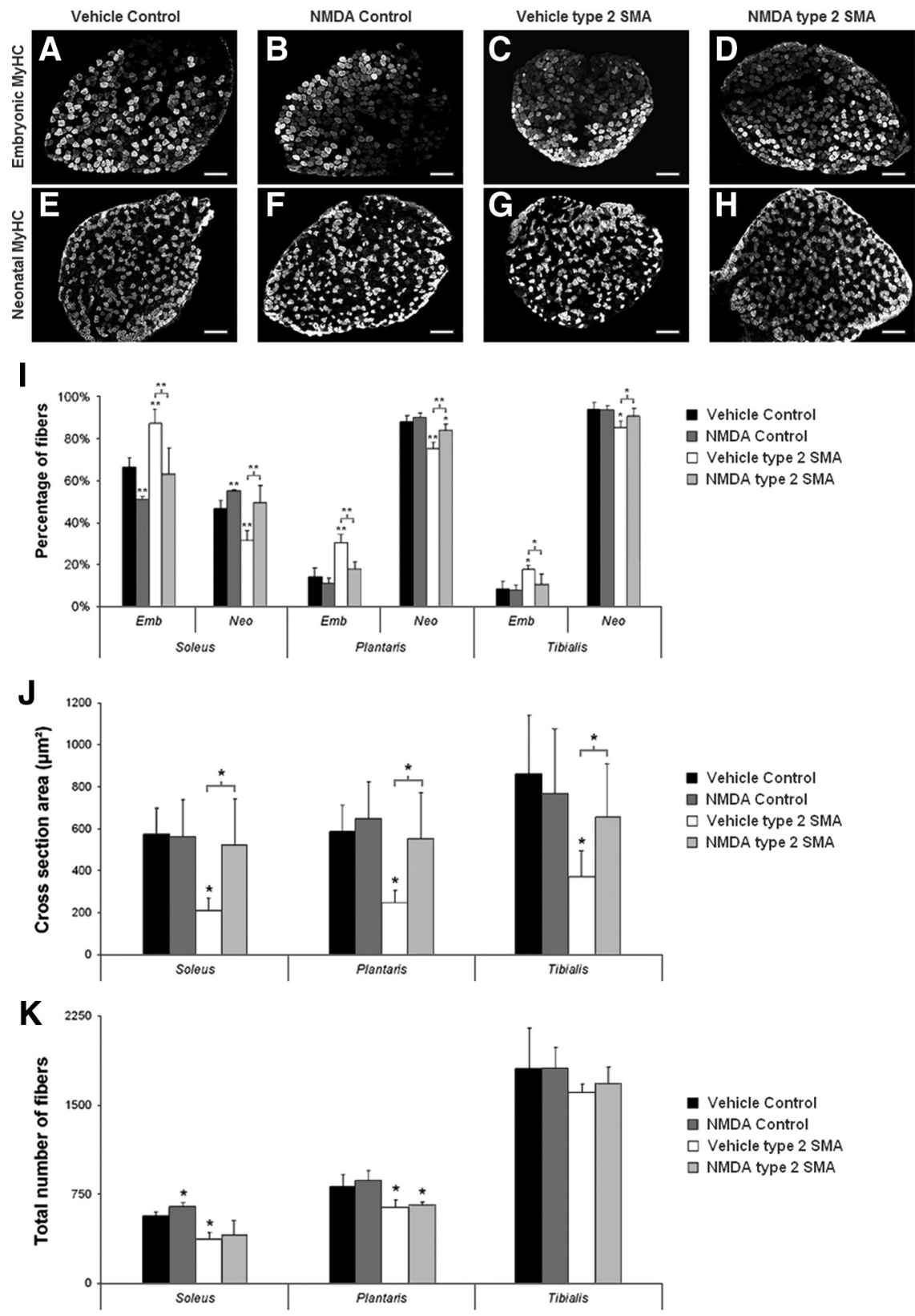

Figure 1. Effect of NMDA treatment on the muscle phenotype of type 2 SMA-like mice. $\boldsymbol{A}-\boldsymbol{H}$, Immunodetection of developmental MyHC isoforms (i.e., embryonic and neonatal) in the soleus of vehicle $(\boldsymbol{A}, \boldsymbol{E})$ - and NMDA-treated control mice $(\boldsymbol{B}, \boldsymbol{F})$ and vehicle $(\boldsymbol{C}, \boldsymbol{G})$ - and NMDA-treated type 2 SMA-like mice $(\boldsymbol{D}, \boldsymbol{H})$ at $12 \mathrm{~d}$ of age. Scale bar, $200 \mu \mathrm{m}$. $\boldsymbol{I}$, Analysis of the embryonic (Emb) and neonatal (Neo) typology of three muscles of the calf (i.e., the soleus, the plantaris, and the tibialis muscles) from vehicle- and NMDA-treated control mice and type 2 SMA-like mice $(n=6)$, at $12 \mathrm{~d}$ of age. ${ }^{*} p<0.05 ;{ }^{* *} p<0.01$. J, Determination of the cross-section area (CSA) of the soleus, the plantaris, and the tibialis from vehicle- and NMDA-treated control and type 2 SMA-like mice $(n=6)$ at $12 \mathrm{~d}$ of age. $\boldsymbol{K}$, Number of muscle fibers in the soleus, plantaris, and tibialis muscles from vehicle- and NMDAtreated control and type 2 SMA-like mice $(n=6)$ at $12 \mathrm{~d}$ of age. Error bars indicate SD.

jective UPlan FL N 0.13), 100 (10× Olympus objective UPlan FL N 0.3), 200 (20× Olympus objective FL N 0.5), 400 (40× Olympus objective UPlan FL N 0.75), 600 (60× Olympus objective UPlanS Apo 1.35 oil), and 1000 (100× Olympus objective UPlanS Apo 1.4 oil) magnifications.

Protein and Western blot analysis. Ventral lumbar spinal cord samples (4-10 mg) were homogenized in $100 \mu \mathrm{l} / 5 \mathrm{mg}$ tissues of ice-cold RIPA buffer [ $50 \mathrm{~mm}$ Tris $\mathrm{HCl}, \mathrm{pH} 8.0,150 \mathrm{~mm} \mathrm{NaCl}, 0.1 \%$ SDS, $0.5 \%$ sodium deoxycholate, 1\% NP-40, 5 mM EDTA, pH 8.0, 2 mm PMSF (phenylmethylsulfonyl fluoride) (Sigma-Aldrich), $50 \mu \mathrm{g} / \mathrm{ml}$ leupeptin, $50 \mu \mathrm{g} / \mathrm{ml}$ pepstatin $\mathrm{A}$, and $50 \mu \mathrm{g} / \mathrm{ml}$ aprotinin]. Protein concentration of the clarified homogenates $\left(4^{\circ} \mathrm{C}, 15 \mathrm{~min}, 13,500 \mathrm{rev} \cdot \mathrm{min}^{-1}\right)$ was determined on all samples using the Bradford protein assay (Bio-Rad Laboratories). Ten 
Vehicle Control

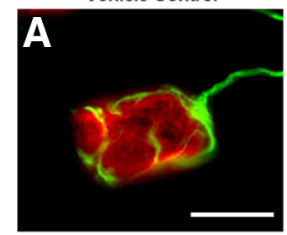

E

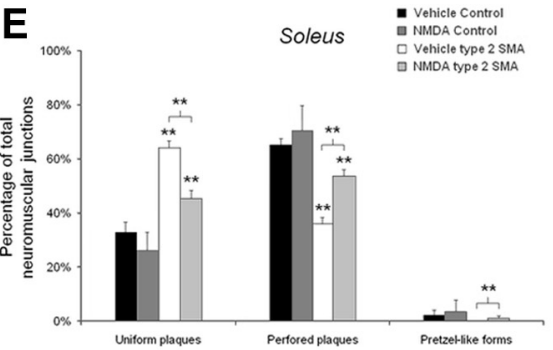

$\mathbf{F}$
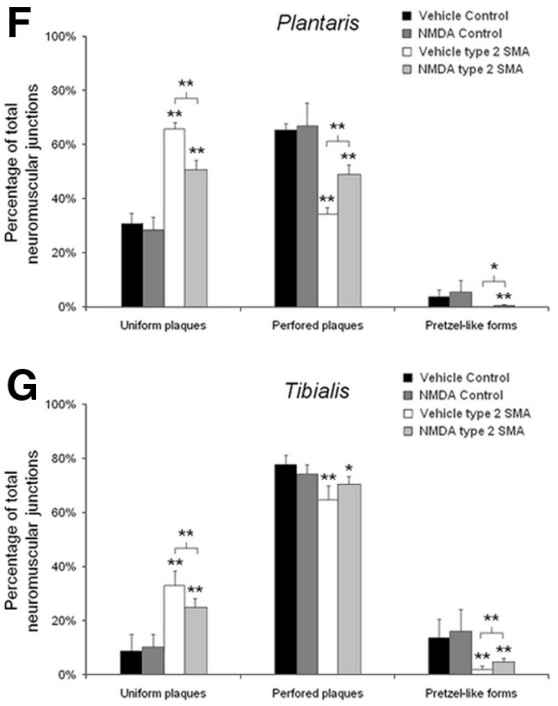

Vehicle type 2 SMA

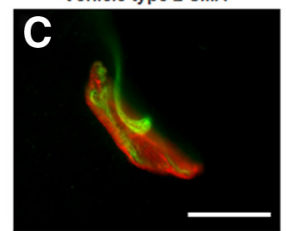

$\mathbf{H}$

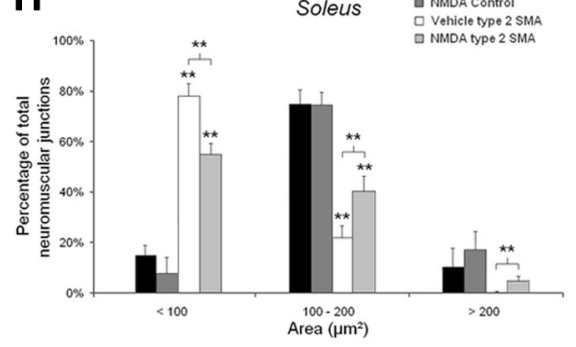

I

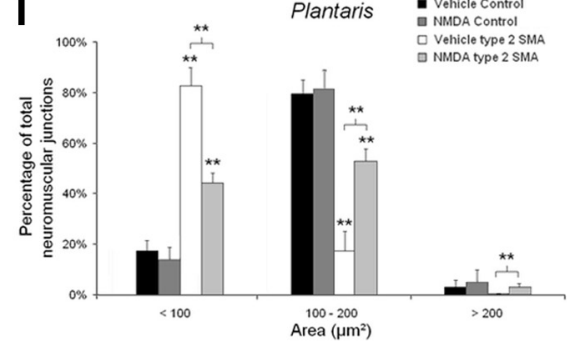

$\mathrm{J}$
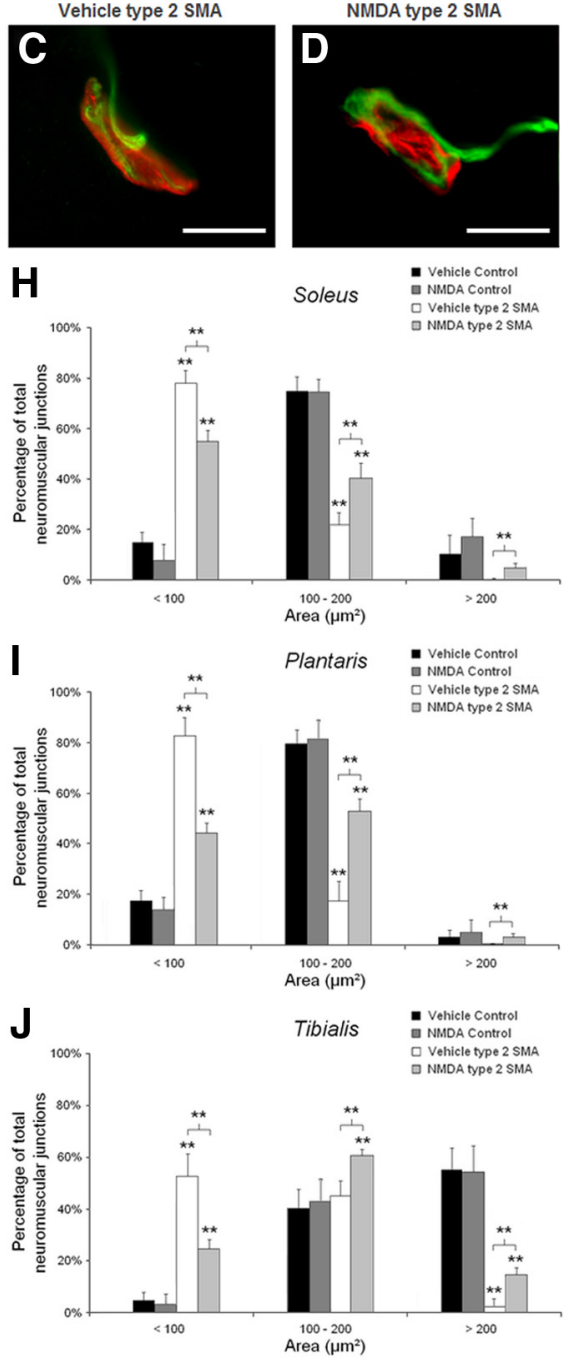

Figure 2. Effect of NMDA treatment on neuromuscular junction maturation in type 2 SMA-like mice. $\boldsymbol{A}-\boldsymbol{D}$, Motor endplate labeling with $\alpha$-bungarotoxin, anti-neurofilament, and anti-synaptophysin antibodies in the soleus of vehicle $(\boldsymbol{A})$ - and NMDAtreated control mice $(\boldsymbol{B})$ and vehicle $(\boldsymbol{C})$ - and NMDA-treated type 2 SMA-like mice $(\boldsymbol{D})$ at $12 \mathrm{~d}$ of age showing a typical pretzel $(\boldsymbol{B})$, perforated $(\boldsymbol{A}, \boldsymbol{D})$, and immature $(\boldsymbol{C})$ type of NMJ. Scale bar, $20 \mu \mathrm{m} . \boldsymbol{E}-\boldsymbol{G}$, Analysis of the neuromuscular junction maturation in the soleus, the plantaris, and the tibialis muscles from vehicle- and NMDA-treated control and type 2 SMA-like mice $(n=5)$ at $12 \mathrm{~d}$ of age. $\boldsymbol{H}-\boldsymbol{J}$, Determination of the neuromuscular junction area in the soleus, plantaris, and tibialis from vehicle- and NMDA-treated control and type 2 SMA-like mice $(n=5)$ at 12 d of age. ${ }^{*} p<0.05 ;{ }^{* *} p<0.01$. Error bars indicate SD.

microgram protein samples for SMN analysis and $30 \mu \mathrm{g}$ samples for other analysis of each homogenate were submitted to $12.5 \%$ SDS-PAGE electrophoresis [ $1.5 \mathrm{~m}$ Tris, $\mathrm{pH} 8.3,12.5 \%$ acrylamide, $0.07 \%$ Bis, $0.1 \%$ SDS, $0.05 \%$ APS (ammonium persulfate), 0.06\% TEMED (tetramethylethylenediamine)]. The separated proteins were transferred on PVDF (polyvinylidene difluoride) membranes (Bio-Rad Laboratories) according to Towbin et al. (1984). Equal loading of samples was checked by Ponceau dye staining of the transferred gels. Western blot analysis was performed on membranes overnight at $4^{\circ} \mathrm{C}$ in $4 \% \mathrm{BSA}, 0.05 \%$ Tween 20 , TBS, pH 7.4. Each of the following primary antibodies, including monoclonal mouse anti-SMN (1:5000; Santa Cruz Biotechnology), polyclonal rabbit antiSer ${ }^{473}$ phospho-AKT (1:1000; Cell Signaling Technology), polyclonal rabbit anti-phospho-ERK1/2 (1: 500; Cell Signaling), polyclonal rabbit anti-Ser ${ }^{133}$ phospho-CREB (1:1000; Millipore), polyclonal rabbit antimyogenin (1:500; Santa Cruz Biotechnology), polyclonal rabbit antitropomyosin (1:5000; Santa Cruz Biotechnology), and polyclonal rabbit anti-caspase 3 (1:1000; Cell Signaling) was incubated overnight at $4^{\circ} \mathrm{C}$ in the above blocking medium. Membranes were rinsed in $0.1 \%$ Tween 20 in TBS three times for $10 \mathrm{~min}$ each time at room temperature and then incubated in horseradish peroxidase-conjugated goat secondary antibody directed against mouse Igs (1:5000; Bio-Rad Laboratories) and in horseradish peroxidaseconjugated goat secondary antibody directed against rabbit Igs (1:10,000; Jackson ImmunoResearch) in $0.1 \%$ Tween 20 in TBS for $1 \mathrm{~h}$ at room temperature. Bound antibody complexes were developed using the ECL system (GE Healthcare) and exposed to Hyperfilm ECL-plus X-ray film (GE Healthcare).

In some instances, membranes were stripped after immunoblotting with phospho-AKT, phospho-ERK, and phospho-CREB by incubation in stripping buffer ( $100 \mathrm{~mm} \beta$-mercaptoethanol, 2\% SDS, $62.5 \mathrm{~mm}$ Tris- $\mathrm{HCl}, \mathrm{pH}$ 6.7) for $30 \mathrm{~min}$ at $55^{\circ} \mathrm{C}$ with agitation, and membranes were then blocked and reprobed with polyclonal rabbit anti-AKT (1:1000; Cell Signaling), polyclonal rabbit anti-ERK1/2 (1:500; Cell Signaling), polyclonal rabbit anti-CREB (1:1000; Millipore), monoclonal mouse antiGAPDH (glyceraldehyde-3-phosphate dehydrogenase) antibody (1:5000; Millipore Bioscience Research Reagents).

Films were quantified with NIH ImageJ, version 1.37 , and the results reported as means \pm SD.

Real-time reverse transcription-PCR analysis. Spinal cord samples were grinded using an Alloy Tool Steel Mortar (Thermo Fisher Scientific) and RNA was extracted using Trizol (Invitrogen) and $1 \mu \mathrm{l}$ of Glycoblue (Ambion) as a carrier. Each RNA preparation was treated with DNase I (DNAfree; Ambion). Reverse transcription (RT) was performed using AMV Reverse Transcriptase (Promega) and random primers (Invitrogen). PCR was performed using GoTaq (Promega) and qPCR was performed using IQ SYBR Green Supermix (Bio-Rad) on a Chromo4 real-time PCR machine (Bio-Rad). The relative amounts of cDNA in samples were determined on the basis of the threshold cycle for each PCR product (Ct) and were normalized to 18S RNA levels.

Sequences of primer sets used for amplification were as follows: SMN2 exon 4-exon 5 segment: E4E5, forward, 5'-TGTGTTGTGGTTTACACTGG-3' , and E4E5, reverse, 5' -TATTTCCAGGAGACCTGGAG-3'; SMN2 exon 6-exon 8 segment: E6E8, forward, 5'-GATGCTGATGCTTTGGGAAG-3', and E6E8, reverse, 5'-GCCTCACCACCGTGCTGG-3'; SMN2 exon 7-exon 8 segment: E7E8, forward, 5'-AAAAAGAAGGAAGGTGCTCAC-3', and E6E8, reverse, 5'-GCCTCACCACCGTGCTGG-3'; 18S: 18S, forward, 5'-GTAACCCGTTGAACCCCATT-3', and 18S, reverse, 5'-CCATCCAATCGGTAGTAGCG-3'.

Statistical analysis. All values are displayed as means and SD within each group (Systat, version 8.0; SPSS). Statistical analysis was performed and comparison between groups were done using ANOVA and post hoc test least significant difference. Survival analysis was performed using Kaplan-Meier analysis.

\section{Results}

The NMDA treatment accelerates skeletal muscle maturation We evaluated the effects of NMDAR activation on the neuromuscular maturation schedule in control and type 2 SMA-like mice. Mice were treated daily by intrathecal injection of NMDA ( 5 $\mathrm{pmol} \cdot \mathrm{g}^{-1}$ ) from $8 \mathrm{~d}$ of age. The progressive acquisition of the adult phenotype by the skeletal muscle was used as a quantitative 
index of the neuromuscular postnatal maturation. Therefore, we analyzed the muscle phenotype of three skeletal muscles including two extensors, the slowtwitch soleus and the fast-twitch plantaris, and one flexor, the fast-twitch tibialis, from control and type 2 SMA-like at $12 \mathrm{~d}$ of age (Fig. 1). The NMDA treatment resulted in a remarkable acceleration of muscle postnatal maturation in SMA-like mice, as evidenced by the NMDAinduced promotion of embryonic to neonatal phenotype shift (Fig. 1I). This phenomenon occurred regardless of both the muscle phenotype (slow-twitch vs fast-twitch) and the muscle function (extensor vs flexor). It should be emphasized that an acceleration of muscle maturation was also observed in control soleus muscles after the NMDA treatment.

Previous experiments in our laboratory have shown that the SMA skeletal muscles display severe atrophy and hypoplasia (Biondi et al., 2008). The present investigation showed that the NMDAR activation limited SMA-induced muscle atrophy, leading to an increase of 248 , 222 , and $177 \%$ in the fiber cross-section area of the soleus, plantaris, and tibialis, respectively, compared with vehicle-treated SMA-like mice $(p<0.05)$ (Fig. $1 J)$. In contrast, no change in the total number of muscle fibers could be detected (Fig. $1 \mathrm{~K}$ ).

\section{The NMDA treatment accelerates} neuromuscular junction maturation

To ensure an accurate description of the motor unit developmental pattern in NMDA-treated versus type 2 SMA-like mice, we have analyzed the structure of the NMJs at $12 \mathrm{~d}$ of age (Fig. 2). During the motor unit postnatal maturation, the postsynaptic organization of the NMJ progressively changes from an immature small uniform plaque of acetylcholine receptors (AChRs) to a perforated large plaque of AChRs that eventually adopts a pretzel form. The changes in the synapse shape were determined for innervated NMJ using $\alpha$-bungarotoxin staining of the three muscles, as previously described (Biondi et al., 2008). Up to 63\% of the NMJs were elliptical, made of uniform plaques of AChRs in the two extensor muscles of the vehicle-treated type 2 SMA-like mice at $12 \mathrm{~d}$ of age. Only $28 \%$ of immature NMJs were found in control muscles $(p<0.01)$, regardless of muscle fiber phenotype. The NMDA treatment improved the NMJ morphology in the three muscles in type 2 SMA-like mice, as demonstrated by the NMDA-induced perforation (Fig. $2 E-G$ ) and enlargement (Fig. $2 H-J)$ of the NMJs on the muscle fibers.

\section{The NMDA treatment protects motor neurons in type 2 SMA-like mice}

Since the NMDA treatment likely accelerated the skeletal muscle maturation, we questioned whether this effect could be beneficial in protecting motor neurons from cell death. Thus, we compared the number of ChAT-positive motor neurons in the ventral spinal cord of control mice and of vehicle- and NMDA-treated
SMA-like mice (Fig. 3). At 12 d of age, a 33\% loss of motor neurons was observed in the vehicle-treated type 2 SMA-like mice compared with untreated controls (Fig. $3 E$ ). In contrast, NMDA-treated type 2 SMA-like mice only showed a $18 \%$ reduction in the number of motor neurons, therefore demonstrating that the NMDA treatment significantly limited the extent of motor neuron death $(p<0.05)$. Furthermore, motor neuron cell body area evaluation provided evidence for a persistent atrophy of motor neurons in the ventral horn of the spinal cord of the vehicle-treated type 2 SMA-like mice compared with control mice at $12 \mathrm{~d}$ of age (Fig. $3 F$ ). In contrast, the extent of atrophy is significantly limited in NMDA-treated mice $(p<0.05)$. No difference could be observed in the number of motor neurons in NMDA- and vehicle-treated control mice at the same age.

To determine whether the NMDA treatment interfered with the apoptotic process in the spinal cord of SMA-like mice, we evaluated the activation of the caspase 3 in the ventral spinal cord of control mice and of vehicle- and NMDA-treated SMA-like mice (Fig. 3G,H). As shown in these figures, the NMDA treatment limited the range of the apoptotic process in SMA-like mouse spinal cord.

\section{The NMDA treatment improves the motor behavior and} prolongs survival of type 2 SMA-like mice

We then questioned whether the cellular benefits of the NMDA treatment would improve the motor behavior of the treated mice. 

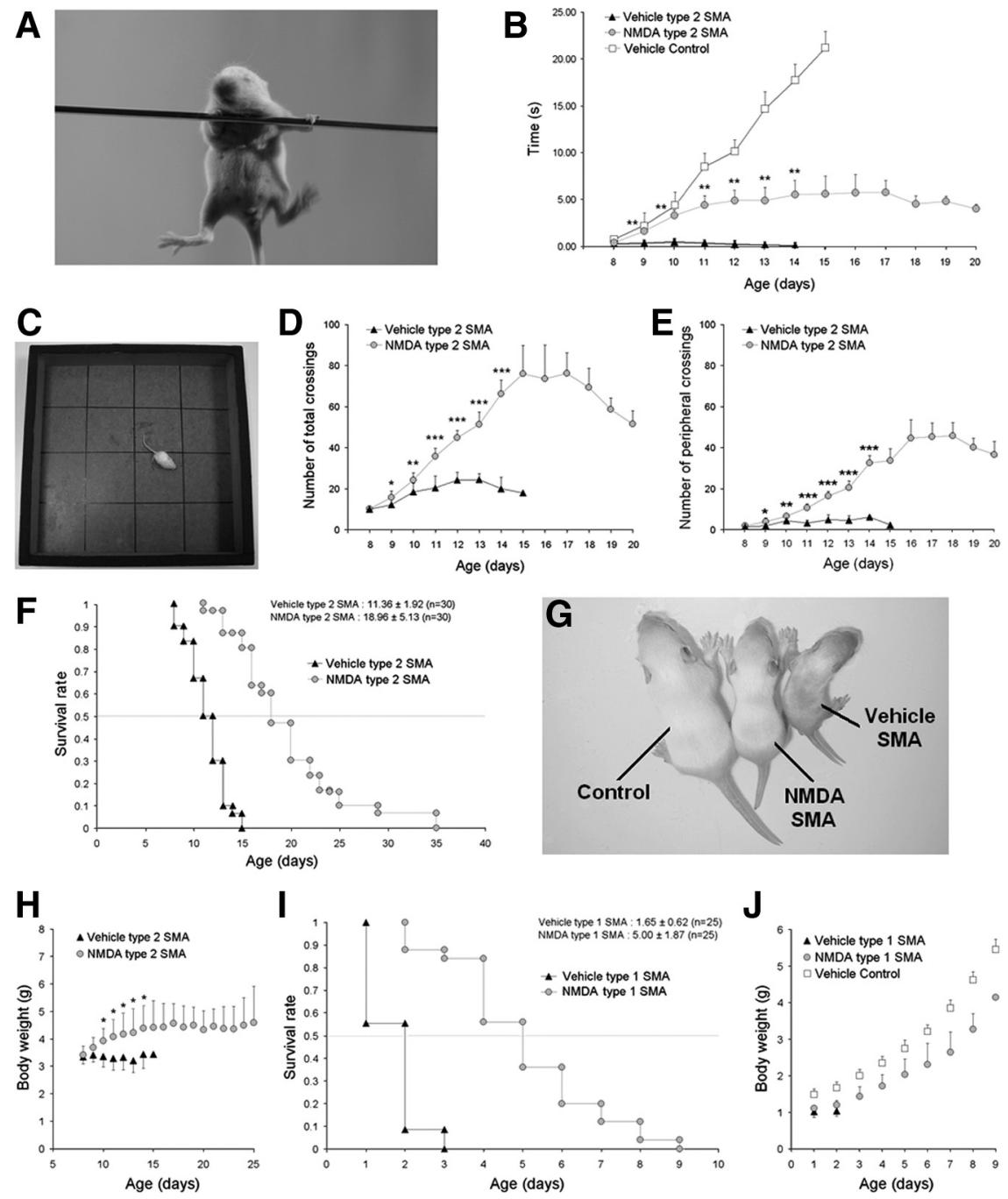

Figure 4. Effect of NMDA on muscle function, life span, and weight curve in SMA-like mice. $\boldsymbol{A}$, Picture showing NMDA-treated type 2 SMA-like mice during a grip test on a metal rod at $12 \mathrm{~d}$ of age. $B$, Grip time of vehicle-, and NMDA-treated type 2 SMA-like mice compared with vehicle-treated controls ( $n=13, n=11$, and $n=15$, respectively). C, Behavior of NMDA-treated type 2 SMA-like mice during an open field test at $12 \mathrm{~d}$ of age. $\boldsymbol{D}$, Total number of crossings during 5 min for the NMDA-treated $(n=13)$ compared with vehicle-treated type 2 SMA-like mice $(n=11)$. $\boldsymbol{E}$, Number of peripheral crossings for the NMDA-treated mice compared with the vehicle-treated mice. $\boldsymbol{F}$, Life span of NMDA-treated $(n=30)$ compared with vehicle-treated type 2 SMA-like mice $(n=30)$. G, Phenotype of control mice (Control) compared with vehicle-treated type 2 SMA-like mice (Vehicle SMA) and NMDA-treated type 2 SMA-like mice (NMDA SMA) at $12 \mathrm{~d}$ of age. $\boldsymbol{H}$, Weight curve in NMDA-treated $(n=20)$ compared with vehicle-treated type 2 SMA-like mice $(n=20)$. $I$, Life span of NMDA-treated $(n=25)$ compared with vehicle-treated type 1 SMA-like mice $(n=25)$. J, Weight curve in NMDA-treated $(n=15)$ compared with vehicle-treated type 1SMA-like mice $(n=15)$ and vehicle-treated control $(n=15) .{ }^{*} p<0.05 ;{ }^{* *} p<0.01 ;{ }^{* *} p<0.001$. Error bars indicate SD. ings between 10 and $12 \mathrm{~d}$ of age $(p<$ 0.01). Interestingly, the NMDAR activation induced a progression in exploratory activity of SMA-like mice with an increase in the total number of peripheral crossings during growth and until $17 \mathrm{~d}$ of age (from 6 to 43 crossings at 10 and $17 \mathrm{~d}$ of age, respectively; $p<0.001$ ).

The impact of the NMDAR activation on the life span of type 2 SMA-like mice was then evaluated. The NMDA treatment significantly increased survival of type 2 SMA-like mice compared with vehicle-treated SMA-like mice (Fig. $4 F)$. The mean survival increased from $11.36 \pm 1.92 \mathrm{~d}$ for the vehicle-treated mice to $18.96 \pm 5.13 \mathrm{~d}$ for the NMDAtreated mice, representing a $66.9 \%$ increase in life span $(p<0.001)$. The type 2 SMA-like mice typically displayed a severe body weight reduction. The NMDA treatment led to a significant and progressive increase in the body weight of SMA-like mice, until 4 or $5 \mathrm{~d}$ before death (Fig. $4 H$ ).

\section{The NMDA treatment is strongly beneficial for the severe type 1 SMA-like mouse model}

To evaluate the therapeutic relevance of the NMDAR activation in SMA, we investigated the effects of the NMDA treatment in another mouse model of SMA, namely the type 1 SMA-like model developed by Monani et al. (2000). A population of 25 type 1 SMA-like mice was treated daily by intrathecal injection of NMDA (5 $\mathrm{pmol} \cdot \mathrm{g}^{-1}$ ) from $1 \mathrm{~d}$ of age and compared with a control population of 25 mutant mice treated with vehicle $(\mathrm{NaCl}, 0.9 \%)$ from $1 \mathrm{~d}$ of age. The NMDA treatment significantly extended the type 1 SMA-like mouse life span that increased from $1.65 \pm 0.62$ to $5 \pm 1.87 \mathrm{~d}$, representing a threefold gain of life span $(p<0.001)$ (Fig. 4I). In addition, during the treatment, SMA-like mice regularly gained weight until death (Fig. $4 J$ ).
We first subjected the mice to a grip test and found that the vehicle-treated SMA-like mice were unable to efficiently grip the metal rod, at any age (Fig. $4 A, B$ ). In contrast, the grip time of the NMDA-treated type 2 SMA-like mice progressively increased to $>5 \pm 0.2 \mathrm{~s}$ until $17 \mathrm{~d}$ of age, but remained lower compared with the vehicle-treated control mice. We then compared the spontaneous activity of the mice in an open field (Fig. 4C-E). After $10 \mathrm{~d}$ of age, vehicle-treated SMA-like mice displayed a strongly reduced exploratory activity compared with agematched controls, with a limited increase in the total number of crossings (18-24 crossings between 10 and $12 \mathrm{~d}$ of age, respectively; $p<0.05)$ and no increase in the number of peripheral crossings $(p>0.05)$. In contrast, the NMDA-treated SMA-like mice displayed a significant increase in the total number of cross-

\section{In vivo $\mathrm{NMDA}$ treatment enhances $\mathrm{SMN}$ protein expression} in the spinal cord of SMA-like mice

Since the cause and the severity of SMA are both related to the expression level of SMN, we analyzed the impact of NMDAR activation on the expression profile of SMN in the spinal cord of the two SMA mouse models. In both strains, the NMDA-induced increase in SMN protein concentration is clearly evidenced by the immunoblot analysis performed at the lumbar spinal cord level (Fig. 5). In type 1 SMA-like mice, a twofold increase in SMN expression level was observed in NMDA-treated mutant mice compared with vehicle-treated SMA-like mice, although this level was lower compared with wild-type controls (Fig. 5A,B). The NMDA-mediated enhancement of SMN expression was also de- 

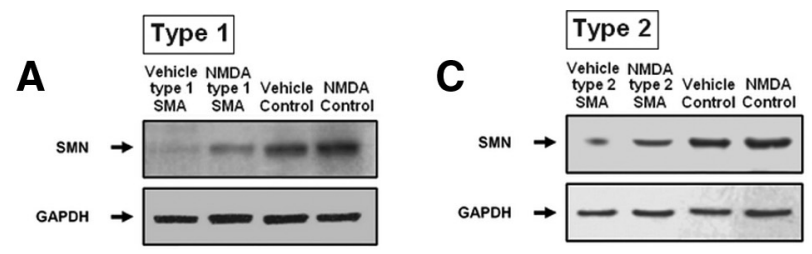

B

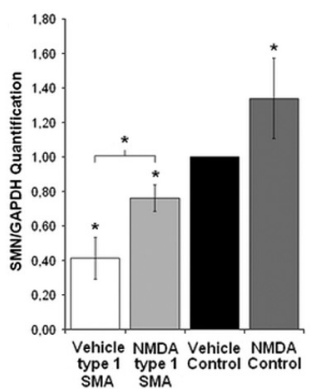

D

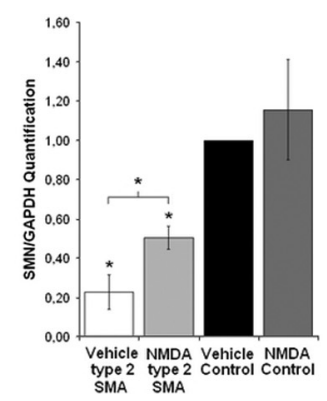

E

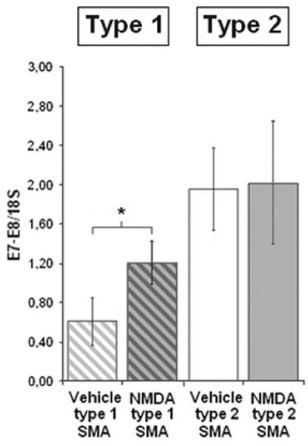

G

Type 1

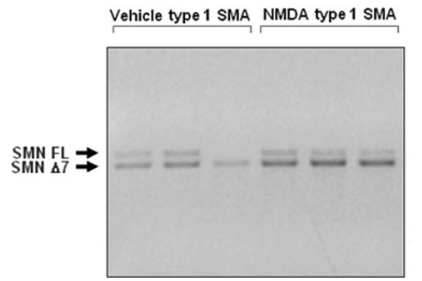

F

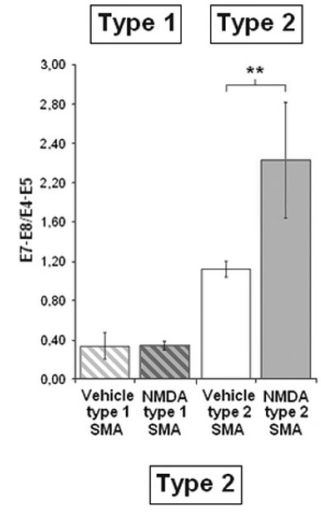

Vehicle type 2 SMA NMDA type 2 SMA

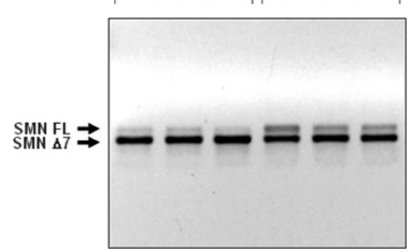

Figure 5. SMN expression in the spinal cord of vehicle- and NMDA-treated SMA-like mice. $\boldsymbol{A}$, $B$, Western blot analysis and quantification of SMN protein expression in the ventral lumbar spinal cord of control mice at $6 \mathrm{~d}$ of age, vehicle type 1 SMA-like mice at $2 \mathrm{~d}$ of age, and NMDA-treated type 1 SMA-like mice at $6 \mathrm{~d}$ of age $(n=3)$. C, $\boldsymbol{D}$, Western blot analysis and quantification of SMN protein expression in the ventral lumbar spinal cord of control mice, vehicle- and NMDA-treated type 2 SMA-like mice at $12 \mathrm{~d}$ of age $(n=4), \boldsymbol{E}, \boldsymbol{F}$, Quantification by real-time RT-PCR of exon 7- exon 8 (E7-E8) segment-containing SMN transcripts normalized to $18 \mathrm{~S}$ transcripts in the ventral lumbar spinal cord of vehicle type 1 and type 2 SMA-like mice at 2 and $12 \mathrm{~d}$ of age, respectively, and of NMDA-treated type 1 and type 2 SMA-like mice at 6 and $12 \mathrm{~d}$ of age, respectively $(\boldsymbol{E})$. Quantification by real-time RT-PCR of exon 7-exon 8 (E7-E8) segment-containing SMN transcripts normalized to exon 4-exon 5 (E4-E5) segmentcontaining SMN transcripts in the ventral lumbar spinal cord of vehicle type 1 and type 2SMAlike mice at 2 and $12 \mathrm{~d}$ of age, respectively, and of NMDA-treated type 1 and type 2 SMA-like mice at 6 and $12 \mathrm{~d}$ of age, respectively $(\boldsymbol{F})$. $\boldsymbol{G}, \mathrm{RT}$-PCR analysis of SMN full-length transcripts (SMN FL, $392 \mathrm{nt}$ ) and SMN transcripts lacking exon 7 (SMN $\Delta 7,338 \mathrm{nt}$ ) in the ventral lumbar spinal cord of vehicle type 1 SMA-like mice at $2 \mathrm{~d}$ of age and NMDA-treated type 1 SMA-like mice at 6 d of age. $\boldsymbol{H}$, RT-PCR analysis of SMN full-length transcripts (SMN FL, 392 nt) and SMN transcripts lacking exon 7 (SMN $\Delta 7,338 \mathrm{nt}$ ) in the ventral lumbar spinal cord of vehicle- and NMDA-treated type 2 SMA-like mice at 12 d of age. ${ }^{*} p<0.05$; ${ }^{* *} p<0.01$. Error bars indicate SD.

tected in controls treated from $\mathrm{P} 1$ and analyzed at $6 \mathrm{~d}$ of age. In type 2 SMA-like mice, the NMDA-induced SMN expression corresponded to a twofold increase compared with vehicle-treated SMAlike mice, although this level was lower compared with wild-type controls (Fig. 5C,D). No significant NMDA effect on SMN expression could be detected in controls treated from $8 \mathrm{~d}$ of age.

To determine whether the increased SMN protein level resulted from an activation of SMN2 gene expression and/or from a modulation of the exon 7 insertion in the SMN transcripts, we quantified the fraction of exon 7-containing mRNA inside the population of SMN transcripts using real-time RT-PCR aimed at amplifying either the exon 7-exon 8 segment (E7-E8) or the exon 4-exon 5 segment (E4-E5) in the ventral spinal cord of vehicle- and NMDA-treated type 1 and type 2 SMA-like mice (Fig. $5 E-H$ ). Unexpectedly, the NMDA treatment provided a differential effect depending on the SMA type. In type 1 SMA-like mice, the NMDAR activation induced a twofold increase in SMN2 gene expression. In contrast, this treatment had no detectable effect on exon 7 inclusion in SMN transcripts. Conversely, in type 2 SMA-like mice, the NMDA treatment, which had no detectable effect on SMN2 gene transcription, did increase the relative level of exon 7-containing SMN transcripts. These results were further confirmed by a classic RT-PCR approach aimed at amplifying the exon 6 -exon 8 segment (E6-E8) (Fig. 5G,H).

\section{The $\mathrm{Ca}^{2+}$ signaling is involved in NMDA-induced SMN expression in SMA spinal cord}

To investigate the molecular pathways that lay downstream the NMDAR, we developed an in vitro protocol, based on the coculture of spinal cord explants from severe SMA and control embryos (E10.5) grown on a monolayer of contractile muscle fibers (muscle cell line MBI) (Cartaud et al., 2004). Approximately 150 neuromuscular junctions per explant could be seen after $20 \mathrm{~d}$ of culture in SMA and control preparations (Fig. 6A,B). The NMDA treatment of the cocultures induced a strong increase (fivefold) of SMN protein expression in the SMA explants, after $5 \mathrm{~d}$ of treatment by $100 \mu \mathrm{M}$ NMDA (Fig. $6 C, D$ ). To ascertain that the SMN protein increase was solely attributable to NMDAR activation, we treated the SMA explants with NMDA in presence of the NMDAR antagonist MK801 (10 $\mu \mathrm{M})$. Specific inhibition of NMDARs blocked the NMDA-mediated increase of SMN expression. The same effects were observed in control explants albeit to a lower range.

Because $\mathrm{Ca}^{2+}$ influx through NMDARs is important in downstream signaling after synaptic activity (Hardingham et al., 2001), we explored its role in NMDA-induced increase of SMN expression in control and SMA explants (Fig. 6C,D). Chelating extracellular $\mathrm{Ca}^{2+}$ by EGTA completely blocked the NMDAinduced activation of SMN protein expression in SMA explants. To evaluate more accurately the role of the $\mathrm{Ca}^{2+}$ influx through the NMDAR, we analyzed the effects of the cell-permeable $\mathrm{Ca}^{2+}$ chelator BAPTA-AM. The inhibition of the $\mathrm{Ca}^{2+}$ cell signal abolished the NMDA-induced increase of SMN expression. Similarly, in control explants, blocking the $\mathrm{Ca}^{2+}$ influx prevented the NMDA-mediated SMN increase of expression.

Since CaMKII, which is present at excitatory postsynaptic compartments, transduces $\mathrm{Ca}^{2+}$ signals generated by NMDARs (Fukunaga et al., 1992), we examined the involvement of CaMKII in the NMDA-induced increase in SMN expression in SMA spinal cords. We first analyzed the phosphorylation status of CaMKII in the spinal cord after in vivo NMDAR activation in type 1 (Fig. 6E,F) and type 2 SMA-like mice (Fig. 6G,H). The NMDA treatment induced a threefold and a twofold increase of the phosphorylated form of CaMKII in type 1 and type 2 SMA-like mice, respectively, compared with vehicle-treated SMA spinal cords. A NMDA-mediated increase of CaMKII phosphorylation was also 

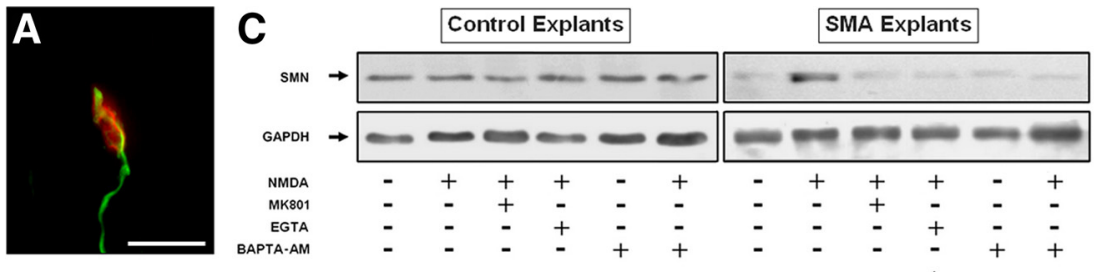

D
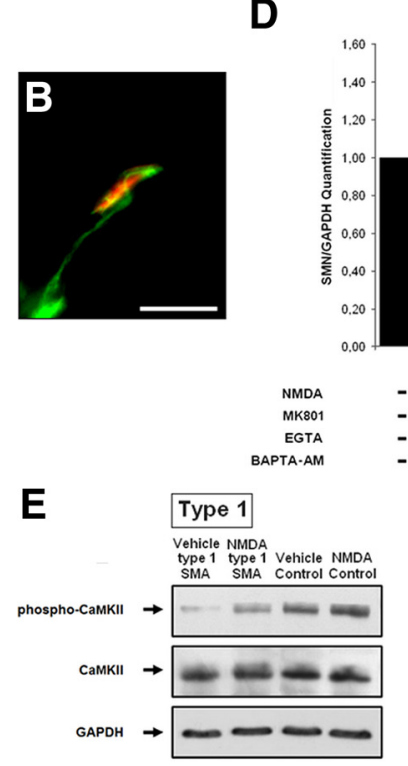

$\mathbf{F}$
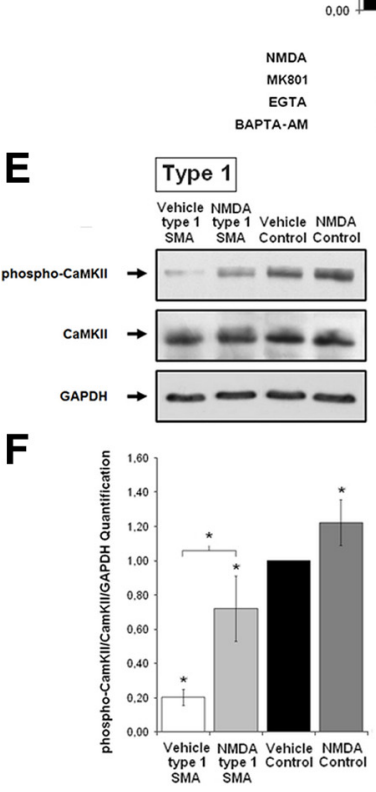

H
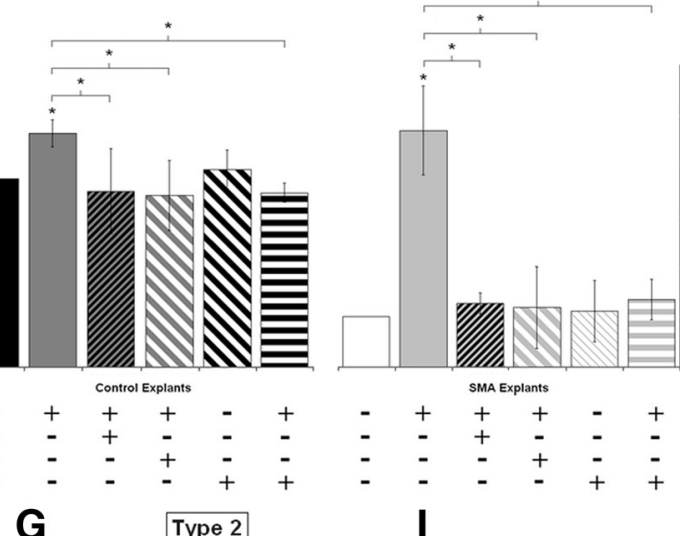

G
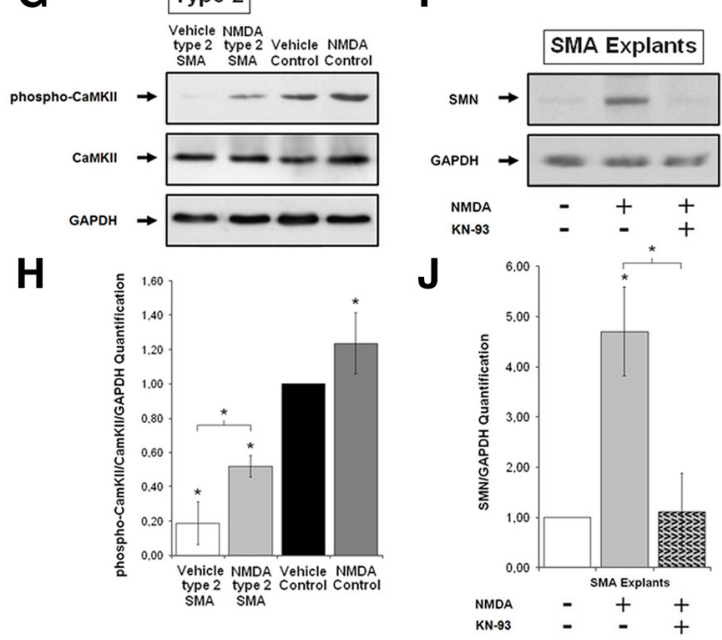

Figure 6. Evaluation of the role of the $\mathrm{Ca}^{2+}$ signaling in NMDA-induced SMN expression in SMA spinal cord and SMA explants. $\boldsymbol{A}, \boldsymbol{B}$, Labeling of neuromuscular junctions with $\alpha$-bungarotoxin, anti-neurofilament, and anti-synaptophysin antibodies in control $(\boldsymbol{A})$ and SMA $(\boldsymbol{B})$ spinal cord explants showing similar structures. Scale bar, $20 \mu \mathrm{m}$. $\boldsymbol{C}, \boldsymbol{D}$, Western blot analysis and quantification of SMN protein expression in control and SMA spinal cord explants in presence or not of NMDA, MK801, and calcium chelators EGTA and BAPTA-AM $(n=3)$. $\boldsymbol{E}, \boldsymbol{F}$, Western blot analysis and quantification of CaMKII protein phosphorylation in the ventral lumbar spinal cord of control mice at $6 \mathrm{~d}$ of age, of vehicle type 1 SMA-like mice at $2 \mathrm{~d}$ of age, and NMDA-treated type 1 SMA-like mice at $6 \mathrm{~d}$ of age $(n=3) . \mathbf{G}, \boldsymbol{H}$, Western blot analysis and quantification of CaMKII protein phosphorylation in the ventral lumbar spinal cord of control mice, vehicle- and NMDA-treated type 2 SMA-like mice at $12 \mathrm{~d}$ of age $(n=3)$. I, J, Western blot analysis and quantification of SMN protein expression in SMA spinal cord explants in presence or not of NMDA and CaMKII inhibitor KN-93 $(n=3)$. ${ }^{*} p<0.05$. Error bars indicate SD.

observed in control spinal cord. We next analyzed the effects of the specific inhibition of CaMKII activity by KN-93 $(10 \mu \mathrm{M})$ in cocultures from SMA spinal cords. We found that inhibition of CaMKII blocked the NMDA-induced increase of SMN expression in SMA explants (Fig. 6I,J).

$\mathrm{Ca}^{2+} /$ calmodulin signaling is therefore an essential requirement for triggering NMDA-dependent SMN expression activation in SMA spinal cords.

The phosphatidylinositol 3-kinase-AKT pathway, but not the MAPK-ERK pathway, mediates SMN expression evoked by NMDAR activation in SMA spinal cord

Among the potential prosurvival pathways triggered by NMDAR activity, the PI3K-AKT kinase cascade is one of the most reported signaling pathway in a number of neuronal cells (Brunet et al., 2001; Lafon-Cazal et al., 2002). In addition, PI3K can be activated in a $\mathrm{Ca}^{2+}$-dependent manner by CaMKII (Sutton and Chandler, 2002). We then questioned whether the PI3K/ AKT signaling pathway is involved in the NMDA-induced increase of SMN protein expression. We first analyzed the phosphorylation status of the AKT kinase, a key target of PI3K, implicated as the transducer of PI3K-dependent survival signals (Franke et al., 1997). Interestingly, the state of AKT phosphorylation was consistently lower in the spinal cord of type 1 (Fig. $7 A, B$ ) and type 2 (Fig. 7C,D) SMAlike mice, compared with control. The in vivo NMDA treatment of the spinal cord of type 1 and type 2 SMA-like mice increased the phosphorylation of AKT by more than twofold. Accordingly, the p$\mathrm{AKT} /$ total AKT ratio increased after the NMDA treatment compared with vehicletreated SMA-like mice, reflecting an increase in the activity level of AKT. Pretreatment of the cocultures with LY294002 $(10 \mu \mathrm{M})$, a selective inhibitor of PI3K, completely blocked the NMDA-induced increase of SMN expression, thus demonstrating that NMDA-induced SMN expression in SMA spinal cord is $\mathrm{PI} 3 \mathrm{~K} /$ AKT dependent (Fig. $7 E, F$ ).

Since the MAPK-ERK pathway has also been implicated in the survival of neuronal cells (Xia et al., 1995; Hetman et al., 1999) and is a target for active CaMKII (Chandler et al., 2001), we examined whether the in vivo NMDA treatment led to ERK1/2 activation in the spinal cord of type 1 and type 2 SMA-like mice. Western blot analysis using both a phospho ( $\left.\mathrm{Thr}^{202} / \mathrm{Tyr}^{204}\right)$ and a dephospho-specific $\mathrm{P}^{44 / 42}$ MAPK antibody showed that NMDA treatment was unlikely to activate ERK in SMA spinal cords (Fig. 7G-J). Accordingly, pretreatment of the cocultures with the MEK inhibitor U0126 (10 $\mu \mathrm{M})$, which significantly inhibited ERK1/2 activation, had no detectable effect on NMDA-induced SMN expression in SMA explants (Fig. $7 K, L$ ).

\section{NMDA treatment stimulates CREB phosphorylation in SMA spinal cord}

A key mediator of activity-dependent gene transcription is the transcription factor CREB, which binds to the cAMP response element (CRE) (Lonze and Ginty, 2002). CRE-dependent gene expression is strongly induced by synaptic NMDAR activity (Hardingham et al., 2002). Interestingly, several CRE sites have been identified in the Smn promoter (Monani et al., 1999), and CRE was shown to function as positive regulator of SMN expression in vitro (Majumder et al., 2004). Therefore, we tested whether in vivo and in vitro activation of NMDARs triggered 
phosphorylation of CREB in type 1 and type 2 SMA-like mice and in coculture with SMA explants (Fig. 8). Immunoblotting with an antibody that specifically recognizes CREB phosphorylation at $\mathrm{Ser}^{133}$ revealed that the NMDAR activation resulted in a more than twofold increase in CREB phosphorylation in type 1 (Fig. $8 A, B$ ) and type 2 (Fig. $8 C, D$ ) SMA-like mice compared with vehicle-treated SMA-like mice. NMDA-induced phosphorylation of CREB was inhibited when SMA explants were incubated with MK801, with the $\mathrm{Ca}^{2+}$ chelator BAPTA-AM, with the PI3K inhibitor LY294002, or with the CaMKII inhibitor KN-93, but not with the ERK inhibitor U0126 (Fig. 8E,F).

\section{Discussion}

As evidenced by the activity-dependent development of neurons within several regions of the nervous system (Crair and Malenka, 1995; Kirkwood and Bear, 1995), motor neurons undergo NMDARmediated molecular and morphologic development during the critical period of early postnatal life (Kalb and Hockfield, 1992; Kalb, 1994). We reported here that, in addition to its strictly neuronal effect, the NMDA-mediated acceleration of motor neuron development is directly involved in the whole motor unit development, including the promotion of the skeletal muscle maturation. These data are particularly relevant in the specific context of SMA, since accumulating data in patients (Martínez-Hernández et al., 2009) and in SMA mouse models (Biondi et al., 2008; Kariya et al., 2008; Kong et al., 2009) have revealed developmental defects with a particular impact of the postnatal maturation of the motor unit. Indeed, although no obvious difference in the development schedule was observed in the motor units of type 1 SMA-like mice at birth (McGovern et al., 2008), a significant delay was observed thereafter in the same strain (Kariya et al., 2008). A poor activity of the motor unit as seen in SMA might interfere with the postnatal maturation, worsening the effects of the lack of SMN. A treatment with a toxic dose of NMDA $\left(25 \mathrm{pmol} \cdot \mathrm{g}^{-1}\right)$ still accelerated motor unit postnatal maturation, but was unable to enhance SMN expression and to alleviate disease symptoms in type 2 SMA-like mice (supplemental Fig. 3, available at www.jneurosci.org as supplemental material). These results are likely attributable to the promotion of apoptotic pathways, as seen by analysis of the caspase 3 pattern of activation and to the inhibition of prosurvival pathways, as seen by the downregulation of AKT phosphorylation in the spinal cord of toxic NMDA dose-treated mice (supplemental Fig. 3, available at www.jneurosci.org as supplemental material). Nevertheless, these results suggest that $\mathrm{SMN}$ is not directly involved the NMDA-induced promotion of motor unit development.

The present study reports for the first time that the in vivo and direct activation of the NMDARs can efficiently protect motor neurons from death in SMA mouse model spinal cord. These data are consistent with previous studies showing neuroprotective effects of low doses of NMDA in the embryonic brain and spinal cord (Kalb and Hockfield, 1992; Kalb, 1994; Ikonomidou et al., 1999, 2000; Hardingham and Bading, 2003). The NMDAinduced promotion of motor neuron survival in SMA spinal cord likely occurs through the activation of the predominantly antiapoptotic PI3K/AKT pathway. Importantly, we have observed a decrease in the phosphorylated-active form of AKT and in one of its main target protein CREB in SMA spinal cord from both type 1 and type 2 SMA-like mice. Consequently, the beneficial effects of the NMDA treatment for SMA-like mice might be also related to an activation of the AKT/CREB prosurvival cascade, which likely counteracts the caspase cascade activation and the motor neuron death as found in the spinal cord of NMDA-treated type 2 SMA-like mice. This hypothesis is consistent with the fact that, under higher activation of the spinal NMDARs, the pattern of AKT activation was comparable with those of the vehicle SMAlike mice, and the neuroprotective potential of NMDAR activa- 

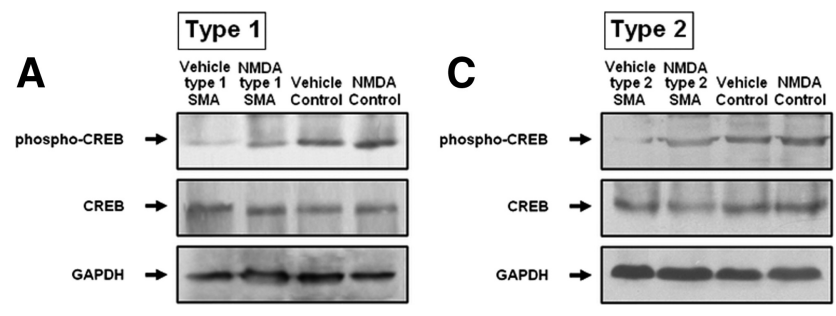

B

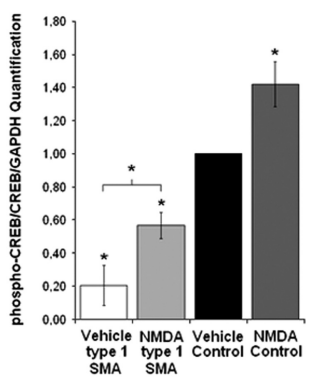

D
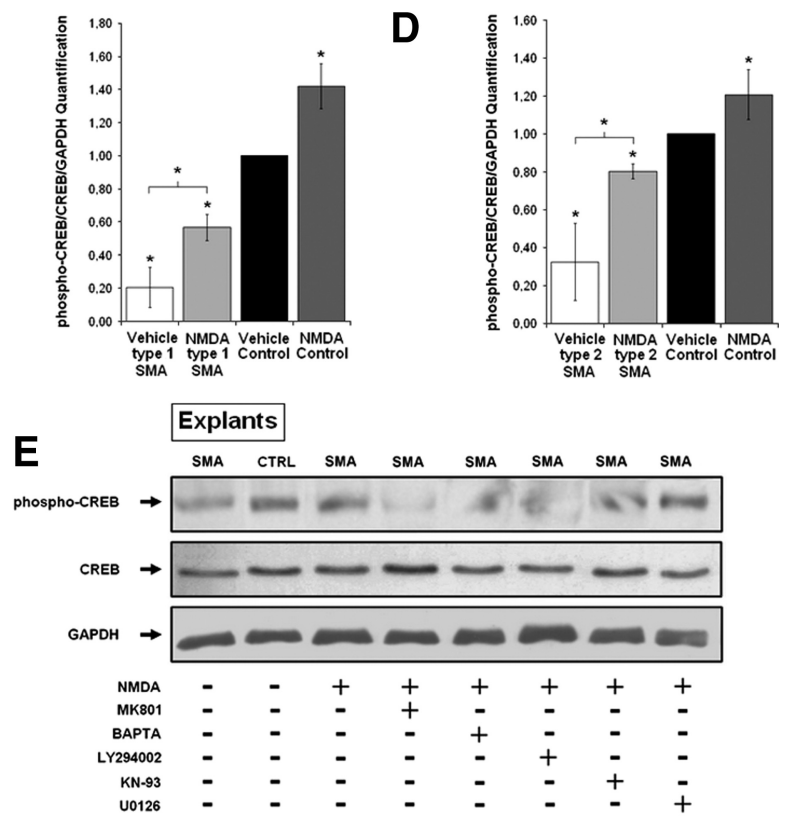

$\mathbf{F}$

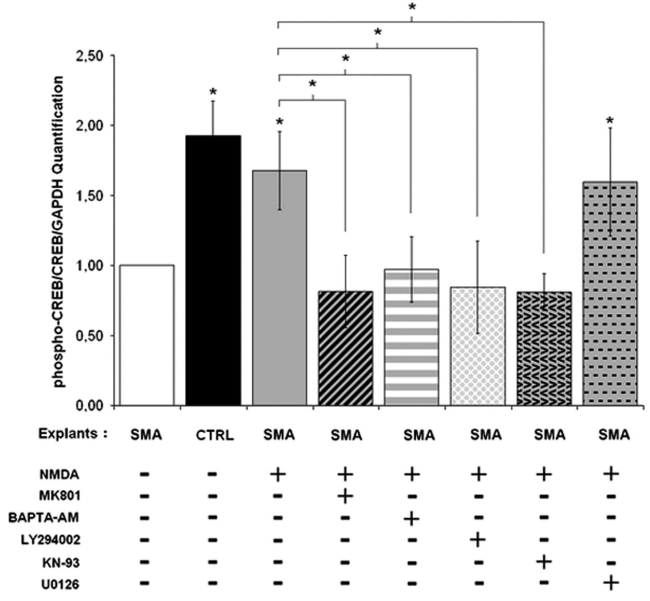

Figure 8. Evaluation of CREB phosphorylation in NMDA-induced SMN expression in SMA spinal cord and SMA explants. $\boldsymbol{A}, \boldsymbol{B}$, Western blot analysis and quantification of CREB protein phosphorylation in the ventral lumbar spinal cord of control mice at $6 \mathrm{~d}$ of age, of vehicle type 1 SMA-like mice at $2 \mathrm{~d}$ of age, and NMDA-treated type 1 SMA-like mice at $6 \mathrm{~d}$ of age $(n=3) . \boldsymbol{C}, \boldsymbol{D}$, Western blot analysis and quantification of CREB protein phosphorylation in the ventral lumbar spinal cord of control mice, vehicle-and NMDA-treated type 2 SMA-like mice at 12 d of age ( $n=$ 3). $\boldsymbol{E}, \boldsymbol{F}$, Western blot analysis and quantification of CREB protein phosphorylation in the control and SMA spinal cord explants in presence or not of NMDA, MK801, BAPTA-AM, PI3K inhibitor LY294002, CaMKII inhibitor KN-93, and ERK inhibitor U0126 $(n=3) .{ }^{*} p<0.05$. Error bars indicate SD.

tion was lost (supplemental Fig. 3, available at www.jneurosci.org as supplemental material). In all likelihood, our study further substantiates the concept that in vivo NMDAR activation might have two opposite effects on motor neuron survival, depending of the level of its activation. Indeed, although low NMDAR activation triggered AKT phosphorylation in SMA spinal cord, cor- relating with a significant decrease of caspase activation, a treatment with a toxic dose of NMDA decreased AKT phosphorylation, resulting in the promotion of motor neuron death (supplemental Fig. 3, available at www.jneurosci.org as supplemental material). A dose effect in the physiology of the NMDAR has been previously reported in cultured cortical neurons on the basis of the pattern of CREB phosphorylation (Lee et al., 2005). Therefore, taking into account this biphasic effect in which both the near absence of and the excessive NMDAR activation could be harmful, an appropriately dosed NMDA treatment of SMA spinal cord might reinitiate a beneficial NMDAR signaling for motor neurons, without reaching a level that could induce neuron apoptosis.

In addition, we report here a complete in vivo characterization of an intracellular pathway activated downstream the NMDARs in the ventral spinal cord and leading to the activation of SMN2 gene expression. We have found that the $\mathrm{Ca}^{2+}$-dependent activation of the PI3K/AKT signaling pathway, but not the ras/ MAPK pathway, leads to the NMDA-induced phosphorylation of CREB and then to the increased SMN gene expression in the ventral spinal cord of type 1 SMA-like mice. These results contrast with the chain of events in cultured cortical neurons, in which the NMDA-mediated activation of CREB depends on ERK activation (Lee et al., 2005), suggesting a cell specificity in the activation of signaling pathways downstream the NMDAR. The $\mathrm{Ca}^{2+}$ influx through the low-activated NMDARs regulates CaMKII, which activation proved to be essential for NMDAinduced SMN2 gene activation of expression. Indeed, a toxic NMDA dose does reduce CaMKII activity (supplemental Fig. 3, available at www.jneurosci.org as supplemental material), suggesting that CaMKII might determine which NMDAR-mediated cellular response will occur, either apoptosis or survival. These results account for those reported in cultured rat hippocampal cells in which a treatment with toxic doses of NMDA induced a reduction of CaMKII activation (Morioka et al., 1995). Interestingly for SMA, in addition to its kinase activity, CaMKII is also known to directly bind with actin and to induce the actin cytoskeleton reorganization in cultured neurons (Shi and Ethell, 2006), leading to the control of filipodia extension and branching as well as the control of the number of synapses (Fink et al., 2003). Thus, in the spinal cord of NMDA-treated SMA-like mouse models, activated CaMKII may stabilize motor neuron cytoskeleton, thus participating in the maintenance of the motor units.

Finally, the NMDA treatment led to a remarkable increase of SMN protein rate in SMA spinal cord. Interestingly, depending on the SMA-like mouse strain, the NMDAR activation resulted in either a strictly transcriptional (type 1 SMA-like mice) or a strictly posttranscriptional (type 2 SMA-like mice) effect on SMN expression. This difference in NMDA effects may be related to the characteristics of the SMN2 transgene used in each mouse model [i.e., a transgene containing only the human SMN2 gene in type 1 SMA-like mice (Monani et al., 2000) or a transgene including the human SMN2 gene and the neighboring genes in the type 2 SMAlike mice (Hsieh-Li et al., 2000) ]. It could be speculated that, since alternative splicing is sometimes coupled with transcription rate (Allemand et al., 2008), the genomic context may contribute to the differential effects observed after NMDA treatment in each model. Alternatively, the differential effect of NMDA might be attributable to the time course of NMDA administration, immediately after birth or from $8 \mathrm{~d}$ of age, in type 1 and type 2 SMA-like mice, respectively. This hypothesis accounts for the developmental regulation of Smn gene expression (Germain-Desprez et al., 2001; Gabanella et al., 2005), substantiating the idea that different 
molecular mechanisms, including trans-acting factors or cisacting events, would be functional at specific time intervals during the postnatal maturation of motor neurons. In this context, on the basis of the present data, CREB might represent a key protein for the modulation of SMN2 gene transcription in neonatal SMA spinal cord. Indeed, activated at birth by the NMDA treatment, CREB might bind to the SMN2 gene promoter, which harbors two functional CRE sites considered essential for Smn gene transactivation (Majumder et al., 2004). The molecular basis of the time-dependent NMDA-induced SMN2 transgene expression remains to be investigated. Furthermore, additional identification of the molecular mechanisms that are triggered by NMDAR activation and result in the promotion of exon 7 inclusion in SMN transcripts opens the way to develop new therapeutic strategy for SMA. It should be noted that, in this context, the NMDA treatment mimics the effects of a running-based training in the same SMA-like mouse strain (Grondard et al., 2005), suggesting the activation of common intracellular mechanisms in electrically stimulated motor neurons.

Together, all these results indicate that the adequate activation of the NMDARs in the SMA mouse spinal cord could be considered as an efficient means of promoting SMN gene expression, leading to an increase in survival and in motor capacities. Importantly, the beneficial effects of the NMDA treatment was observed in two different SMA mouse models, which were differently engineered in terms of Smn gene invalidation (exon 2 or exon 7 targeted in type 1 and type 2 SMA-like mice, respectively) and of SMN2 transgene (only SMN2 or a larger genomic region in type 1 and type 2 SMA-like mice, respectively) (Hsieh-Li et al., 2000; Monani et al., 2000). Needless to say, the transposition of our results collected in animal models to human patients is beyond the scope of this study. The determination of the nociceptive threshold and the efficient doses of NMDA constitute an absolute preliminary requirement conditioning the use of NMDA or NMDA receptor agonists in human SMA patients.

\section{References}

Allemand E, Batsché E, Muchardt C (2008) Splicing, transcription, and chromatin: a ménage à trois. Curr Opin Genet Dev 18:145-151.

Andreassi C, Patrizi AL, Monani UR, Burghes AH, Brahe C, Eboli ML (2002) Expression of the survival of motor-neuron (SMN) gene in primary neurons and increase in SMN levels by activation of the $N$-methyl-D-aspartate glutamate receptor. Neurogenetics 4:29-36.

Biondi O, Grondard C, Lécolle S, Deforges S, Pariset C, Lopes P, CifuentesDiaz C, Li H, della Gaspera B, Chanoine C, Charbonnier F (2008) Exercise-induced activation of NMDA receptor promotes motor unit development and survival in a type 2 spinal muscular atrophy model mouse. J Neurosci 28:953-962.

Brunet A, Datta SR, Greenberg ME (2001) Transcription-dependent and -independent control of neuronal survival by the PI3K-Akt signaling pathway. Curr Opin Neurobiol 11:297-305.

Cartaud A, Strochlic L, Guerra M, Blanchard B, Lambergeon M, Krejci E, Cartaud J, Legay C (2004) MuSK is required for anchoring acetylcholinesterase at the neuromuscular junction. J Cell Biol 165:505-515.

Chandler LJ, Sutton G, Dorairaj NR, Norwood D (2001) N-Methyl-Daspartate receptor-mediated bidirectional control of extracellular signalregulated kinase activity in cortical neuronal cultures. J Biol Chem 276:2627-2636.

Crair MC, Malenka RC (1995) A critical period for long-term potentiation at thalamocortical synapses. Nature 375:325-328.

Crawford TO, Pardo CA (1996) The neurobiology of childhood spinal muscular atrophy. Neurobiol Dis 3:97-110.

Fink CC, Bayer KU, Myers JW, Ferrell JE Jr, Schulman H, Meyer T (2003) Selective regulation of neurite extension and synapse formation by the beta but not the alpha isoform of CaMKII. Neuron 39:283-297.

Franke TF, Kaplan DR, Cantley LC, Toker A (1997) Direct regulation of the
Akt proto-oncogene product by phosphatidylinositol-3,4-bisphosphate. Science 275:665-668.

Fukunaga K, Soderling TR, Miyamoto E (1992) Activation of $\mathrm{Ca}^{2+}$ / calmodulin-dependent protein kinase II and protein kinase $\mathrm{C}$ by glutamate in cultured rat hippocampal neurons. J Biol Chem 267:2252722533.

Gabanella F, Carissimi C, Usiello A, Pellizzoni L (2005) The activity of the spinal muscular atrophy protein is regulated during development and cellular differentiation. Hum Mol Genet 14:3629-3642.

Germain-Desprez D, Brun T, Rochette C, Semionov A, Rouget R, Simard LR (2001) The SMN genes are subject to transcriptional regulation during cellular differentiation. Gene 279:109-117.

Grondard C, Biondi O, Armand AS, Lécolle S, Della Gaspera B, Pariset C, Li H, Gallien CL, Vidal PP, Chanoine C, Charbonnier F (2005) Regular exercise prolongs survival in a type 2 spinal muscular atrophy model mouse. J Neurosci 25:7615-7622.

Hardingham GE, Bading H (2003) The yin and yang of NMDA receptor signalling. Trends Neurosci 26:81-89.

Hardingham GE, Arnold FJ, Bading H (2001) Nuclear calcium signaling controls CREB-mediated gene expression triggered by synaptic activity. Nat Neurosci 4:261-267.

Hardingham GE, Fukunaga Y, Bading H (2002) Extrasynaptic NMDARs oppose synaptic NMDARs by triggering CREB shut-off and cell death pathways. Nat Neurosci 5:405-414.

Hetman M, Kanning K, Cavanaugh JE, Xia Z (1999) Neuroprotection by brain-derived neurotrophic factor is mediated by extracellular signalregulated kinase and phosphatidylinositol 3-kinase. J Biol Chem 274:22569-22580.

Hsieh-Li HM, Chang JG, Jong YJ, Wu MH, Wang NM, Tsai CH, Li H (2000) A mouse model for spinal muscular atrophy. Nat Genet 24:66-70.

Ikonomidou C, Bosch F, Miksa M, Bittigau P, Vöckler J, Dikranian K, Tenkova TI, Stefovska V, Turski L, Olney JW (1999) Blockade of NMDA receptors and apoptotic neurodegeneration in the developing brain. Science 283:70-74.

Ikonomidou C, Stefovska V, Turski L (2000) Neuronal death enhanced by $\mathrm{N}$-methyl-D-aspartate antagonists. Proc Natl Acad Sci U S A 97: 12885-12890.

Kalb RG (1994) Regulation of motor neuron dendrite growth by NMDA receptor activation. Development 120:3063-3071.

Kalb RG, Hockfield S (1992) Activity-dependent development of spinal cord motor neurons. Brain Res Brain Res Rev 17:283-289.

Kariya S, Park GH, Maeno-Hikichi Y, Leykekhman O, Lutz C, Arkovitz MS, Landmesser LT, Monani UR (2008) Reduced SMN protein impairs maturation of the neuromuscular junctions in mouse models of spinal muscular atrophy. Hum Mol Genet 17:2552-2569.

Kirkwood A, Bear MF (1995) Elementary forms of synaptic plasticity in the visual cortex. Biol Res 28:73-80.

Kobayashi T, Askanas V, Engel WK (1987) Human muscle cultured in monolayer and cocultured with fetal rat spinal cord: importance of dorsal root ganglia for achieving successful functional innervation. J Neurosci 7:3131-3141.

Kong L, Wang X, Choe DW, Polley M, Burnett BG, Bosch-Marcé M, Griffin JW, Rich MM, Sumner CJ (2009) Impaired synaptic vesicle release and immaturity of neuromuscular junctions in spinal muscular atrophy mice. J Neurosci 29:842-851.

Lafon-Cazal M, Perez V, Bockaert J, Marin P (2002) Akt mediates the antiapoptotic effect of NMDA but not that induced by potassium depolarization in cultured cerebellar granule cells. Eur J Neurosci 16:575-583.

Lee B, Butcher GQ, Hoyt KR, Impey S, Obrietan K (2005) Activitydependent neuroprotection and cAMP response element-binding protein (CREB): kinase coupling, stimulus intensity, and temporal regulation of CREB phosphorylation at serine 133. J Neurosci 25:1137-1148.

Lefebvre S, Bürglen L, Reboullet S, Clermont O, Burlet P, Viollet L, Benichou B, Cruaud C, Millasseau P, Zeviani M (1995) Identification and characterization of a spinal muscular atrophy-determining gene. Cell 80:155-165.

Lladó J, Calderó J, Ribera J, Tarabal O, Oppenheim RW, Esquerda JE (1999) Opposing effects of excitatory amino acids on chick embryo spinal cord motoneurons: excitotoxic degeneration or prevention of programmed cell death. J Neurosci 19:10803-10812.

Lonze BE, Ginty DD (2002) Function and regulation of CREB family transcription factors in the nervous system. Neuron 35:605-623. 
Lorson CL, Androphy EJ (2000) An exonic enhancer is required for inclusion of an essential exon in the SMA-determining gene SMN. Hum Mol Genet 9:259-265.

Majumder S, Varadharaj S, Ghoshal K, Monani U, Burghes AH, Jacob ST (2004) Identification of a novel cyclic AMP-response element (CRE-II) and the role of CREB-1 in the CAMP-induced expression of the survival motor neuron (SMN) gene. J Biol Chem 279:14803-14811.

Martínez-Hernández R, Soler-Botija C, Also E, Alias L, Caselles L, Gich I, Bernal S, Tizzano EF (2009) The developmental pattern of myotubes in spinal muscular atrophy indicates prenatal delay of muscle maturation. J Neuropathol Exp Neurol 68:474-481.

McGovern VL, Gavrilina TO, Beattie CE, Burghes AH (2008) Embryonic motor axon development in the severe SMA mouse. Hum Mol Genet 17:2900-2909.

Monani UR, McPherson JD, Burghes AH (1999) Promoter analysis of the human centromeric and telomeric survival motor neuron genes (SMNC and SMNT). Biochim Biophys Acta 1445:330-336.

Monani UR, Sendtner M, Coovert DD, Parsons DW, Andreassi C, Le TT, Jablonka S, Schrank B, Rossoll W, Prior TW, Morris GE, Burghes AH (2000) The human centromeric survival motor neuron gene (SMN2) rescues embryonic lethality in Smn ${ }^{-1-}$ mice and results in a mouse with spinal muscular atrophy. Hum Mol Genet 9:333-339.

Morioka M, Fukunaga K, Nagahiro S, Kurino M, Ushio Y, Miyamoto E
(1995) Glutamate-induced loss of $\mathrm{Ca}^{2+} /$ calmodulin-dependent protein kinase II activity in cultured rat hippocampal neurons. J Neurochem 64:2132-2139.

Papadia S, Hardingham GE (2007) The dichotomy of NMDA receptor signaling. Neuroscientist 13:572-579.

Papadia S, Stevenson P, Hardingham NR, Bading H, Hardingham GE (2005) Nuclear $\mathrm{Ca}^{2+}$ and the cAMP response element-binding protein family mediate a late phase of activity-dependent neuroprotection. J Neurosci 25:4279-4287.

Shi Y, Ethell IM (2006) Integrins control dendritic spine plasticity in hippocampal neurons through NMDA receptor and $\mathrm{Ca}^{2+} /$ calmodulindependent protein kinase II-mediated actin reorganization. J Neurosci 26:1813-1822.

Sutton G, Chandler LJ (2002) Activity-dependent NMDA receptormediated activation of protein kinase B/AKT in cortical neuronal cultures. J Neurochem 82:1097-1105.

Towbin H, Schoenenberger C, Ball R, Braun DG, Rosenfelder G (1984) Glycosphingolipid-blotting: an immunological detection procedure after separation by thin layer chromatography. J Immunol Methods 72:471-479.

Xia Z, Dickens M, Raingeaud J, Davis RJ, Greenberg ME (1995) Opposing effects of ERK and JNK-p38 MAP kinases on apoptosis. Science 270: $1326-1331$ 